\title{
Cell surface membrane proteins as personalized biomarkers: where we stand and where we are
} headed

Personalized medicine requires the development of a wide array of biomarker diagnostic assays, reflecting individual variations and thus allowing tailored therapeutic interventions. Membrane proteins comprise approximately $30 \%$ of total human proteins; they play a key role in various physiological functions and pathological conditions, although, currently, only a limited number of membrane proteins are applied as biomarkers. In many normal tissues, cell surface membrane proteins are not easily accessible for diagnostic sampling, and tumor-derived membrane preparations - while serving as potential tumor biomarkers - may not reflect physiological protein expression. In addition to post-translational modifications, which may include glycosylation, phosphorylation and lipid modifications, the trafficking of membrane proteins is also regulated. Moreover, a tight cellular quality control monitors membrane protein maturation, and continuous removal and reinsertion, involving special signaling systems, occurs in many cases. However, cell surface membrane proteins already serve as valuable prognostic and predicative biomarkers, for example, in hematological and immunological diseases, by the determination of the cluster of differentiation markers. In this review, we demonstrate the relevance of cell surface membrane biomarkers in various diseases and call attention to the potential application of red blood cell (erythrocyte) membrane proteins in this regard. Surprisingly, red blood cells express hundreds of membrane proteins, which seem to reflect a general genetic and regulatory background, and may serve as relatively stable and easily accessible personalized membrane biomarkers. Quantitative membrane protein detection in red blood cells by flow cytometry may bring a breakthrough in this regard.

KEYWORDS: cluster of differentiation markers erythrocyte membrane proteins as biomarkers membrane channels membrane protein biomarkers membrane receptors membrane transporters processing of membrane proteins trafficking of membrane proteins

\section{Role of membrane proteins in health, disease \& medical diagnostics}

Membrane proteins are key players in many physiological functions and pathological conditions. Classification of membrane proteins may be based on cellular functions, mechanistic approaches, characteristic protein motifs, cellular localization, or even protein interactions or modifications. Without attempting a detailed classification, in this section we call attention to a few groups and representative members of membrane proteins that are especially important modulators of physiological and pathological functions, and/or serve as major diagnostic biomarkers, as well as drug targets in medicine.

Biomarkers are important both in early and precise diagnosis, assessing the progression of a disease, as well as for prediction of the treatment response. Prognostic markers provide a framework to understand disease occurrence and progression, while predictive biomarkers allow the early assessment of potential therapy response; for example, predict the efficacy or the adverse effects of a drug treatment. The so-called 'theranostic' biomarkers combine diagnostic markers with actual therapeutic targets, thus allowing more precise application of specific drugs. In order to accept and adopt an emerging biomarker in clinical practice, evidence for its diagnostic relevance, accuracy and even economic application has to be established [101].

Membrane proteins represent all these various types of biomarkers and are predicted to gain increasing medical diagnostic applications. Owing to the huge number of membrane-based biomarkers, in this review, we focus on the cell surface (plasma membrane) protein families and emphasize their diagnostic aspects.

\section{Membrane receptors}

Membrane receptors are the best known and characterized members, and mostly represent integral membrane protein families. Receptors in the plasma membrane have one or more membranespanning hydrophobic domain and ligand-binding regions for recognizing mostly extracellular ligands.

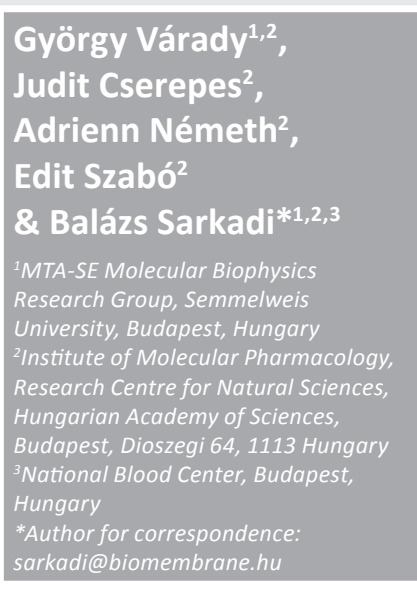

Future
Medicine 
The receptor tyrosine kinases (RTKs) have single transmembrane domains and are activated in most cases by dimerization, resulting in an activated intracellular tyrosine kinase subunit. The human genome contains almost 60 genes coding for RTKs, which participate in a great deal of cellular functions - regulating cell survival, metabolism, proliferation or differentiation. Dysfunctions of RTKs are involved in developmental diseases, diabetes, atherosclerosis and cancer development (for reviews, see $[1,2]$ ). The best characterized RTKs include growth hormone receptors (EGFR-PDGFR, ERBB2, ERBB3 and ERBB4), mostly present in epithelial cells, while FGF hormone receptors (FGFR1-4) are especially involved in the development of the skin and the nervous system [3,4]. Some growth factor receptors, for example, cytokine receptors, do not contain tyrosine kinase domains, but recruit specific kinases (e.g., the JAK-STAT pathway members), which provide the transfer of ligand-dependent signaling.

Membrane-based RTKs are especially important biomarkers in targeted cancer therapies. The uncontrolled activity of RTKs in cancer development has been well established and the related mutations and expression levels of these proteins already serve as important diagnostic markers. Since specific targeted inhibitors of RTKs are successfully used at the clinic [5,6], an early and specific detection of relevant RTKs has become widely accepted. In fact, the determination of HER2 (ERBB2, CD340) overexpression in certain cancer samples is a strong predictive marker for the efficient use of HER2 inhibitors, for example, Herceptin ${ }^{\circledR}$ (trastuzumab). Therefore, the determination of this 'theranostic' biomarker became essential in initiating a specific treatment $[6,7]$.

The G-protein-coupled receptors (GPCRs) comprise another large and well-characterized family of membrane receptors - represented by approximately 800 genes in the human genome. The N-terminal extracellular regions in these proteins form the ligand-binding and-recognition domains. The conformational changes in the receptor protein alter the intracellular binding of heterotrimeric GTP-binding proteins, and the activation of GTP-binding proteins translates the message to intracellular mediator pathways. In addition to their key role in major signaling pathways, such as sensing (e.g., smell, light, hormones or neurotransmitters), numerous drugs and toxins also act through GPCR proteins. Regulation of blood plasma calcium levels and water reabsorption in the kidney are both achieved by the functioning of specific GPCRs [8,9].

Complex regulation of GPCR activity includes phosphorylation, which, often by inducing endocytosis and receptor internalization, specifically downregulates receptor activity. Oligomerization of GPCRs is also a widely observed regulation of activity. All these receptor modulation pathways, which alter localization and protein conformation, are important factors in the use of GPCRs as biomarkers. Interestingly, most of the currently available medicines, whether agonists, antagonists, inverse agonists or allosteric modulators, interact with GPCRs [10-12].

Membrane receptors, sensing extracellular ligands or other signals are often based on the function of transmembrane channel proteins (see below). Ligand- or voltage-activated ion channels are key modulators of cellular ion and water balance, execute information transfer and regulate membrane potential in a variety of cells. The regulated opening and closing of these channels allows the rapid movement of hydrophilic molecules or water through the hydrophobic lipid layers of cellular membranes, by sensing the binding of transmitter molecules or changes in the membrane potential. Activated ion channels may be large polypeptides or complexes of subunits, sensing the signals and executing the channel alterations [13-15]. While antibody recognition is used in many cases for the diagnosis of 'channelopathies', the complex regulation of these channels may again significantly hinder the recognition of molecular alterations. Neurotransmitter ion channels are important drug targets and thus relevant biomarkers in major brain diseases [16]. The 'notorious' potassium channels in cardiac tissues, HERG and KCNQ1, in most cases responsible for long QT syndrome and related drug side effects, are exceptionally important personalized biomarkers in pharmaceutical development projects $[17,18]$. An important member of the modulated ion channels is the CFTR (ABCC7) protein, playing a key role in the development of the lethal heritable disease, cystic fibrosis. A similarly important ion channel complex, formed by the ABCC8 protein and the Kir6.1 potassium channel, senses cellular ATP levels and regulates insulin secretion in pancreatic $\beta$-cells $[19,20]$. Molecular diagnostics for inherited mutations of these proteins are well developed, but protein level and functional diagnostics are still lacking in this area.

Many plasma membrane receptors are large protein complexes, with specific, ligand-induced enzymatic activities. Parts of these complexes, 
represented, for example, by the INSR (INSR) or the bone morphogenic protein receptor (BMPR) are responsible for ligand binding, while other components induce specific activation of serine-threonine kinases, tyrosine kinases or other signal-transducing enzymes [21,22].

\section{Membrane transporter proteins}

Membrane transporter proteins compose another large group of potential biomarkers and therapeutic targets, as approximately $10 \%$ of all human genes are transporter related [102].

Active, ATP-dependent transporters include the P-type ATPases, responsible for the energy-dependent transport of various ions. The Na, K-ATPase family (ATP1A1-4 and ATP1B1-4) has a key role in the establishment of unequal ion distribution; that is, the high cellular $\mathrm{K}$ and low $\mathrm{Na}$ content. The synergistic function of the plasma membrane Ca-ATPases (ATP2B1-4) and the endoplasmic reticulum Ca-ATPases (ATP2A1-3) provide the physiologically low intracellular calcium concentration, the $\mathrm{H}, \mathrm{K}$-ATPase (ATP4A) is a basic component of acid production in the gastric epithelia. Members of the P-type ATPase family (ATP7A and B) are responsible for active cellular copper transport. Although these transporters are essential components of cell survival, partial malfunctions are involved in various disease conditions, and thus they may serve as important biomarkers. The role of $\mathrm{Na}$, K-ATPase mutations were indicated in migraines, in renal diseases and tumors, the mutations in PMCA (ATP2B2) cause heritable deafness and balance disorder, while mutations in the ATP7 proteins cause the Menkes and the Wilson diseases of copper metabolism [23].

The ATP-binding cassette (ABC) transporters, large, integral membrane proteins, containing ATP-binding and -hydrolyzing domains in the intracellular regions, have basic structural similarities, but numerous divergent functions [24]. Primary ATP-dependent active transporters, called multidrug resistance (MDR)-ABC transporters are involved in the active cellular extrusion of hydrophobic xenobiotics and toxic agents. The key MDR-ABC transporters are the ABCB1 protein (MDR1, Pgp), the members of the MRP (ABCC) family, ABCC1 and ABCC2, and the ABCG2 protein (MXR, BCRP). These transporters show a promiscuous recognition and removal of a large number of chemically different compounds, including anticancer drugs. Their physiological localization includes tissue barriers, including the intestine, the blood-brain and the blood-testis barrier and the placenta; and secretory organs, including the liver and the kidney. The transported substrates are various xenobiotics and endobiotics, including partially detoxified drug metabolites. Because of their important function in cancer drug resistance and general drug and toxin metabolism, we emphasize the potential personalized biomarker properties of these ABC proteins. Mutations or polymorphisms of an MDR-ABC transporter may significantly alter the handling of food components, the effects of environmental toxins exposing our body, as well as the absorption, distribution, metabolism, excretion and toxicity (ADME-Tox) properties of a large number of pharmacological agents. The expression of MDR-ABC transporters in cancer cells, especially in cancer stem cells, causes multiple drug resistance, thus the inclusion of these proteins as cancer biomarkers may predict drug response and modify disease prognosis and treatment [25].

Some active ABC transporters have a more specialized function in xenobiotic elimination and drug metabolism. In the liver, the ABCB4 (MDR3) protein is specialized to phospholipid extrusion, ABCB11 (BSEP) transports bile acids, and the ABCG5-ABCG8 heterodimer protein exports cholesterol and phytosterols into the bile canaliculi. Variations in the expression and function of these transporters affect bile secretion and may be involved in progressive liver diseases. The ABCB2-ABCB3 dimer is required for peptide transport and antigen presentation; other $\mathrm{ABC}$ transporters correspond to gated ion channel activities (see above), modulation of reverse cholesterol transport (ABCA1), transportation of surfactant molecules in the lung (ABCA3), transport of retinal in the eye (ABCA4), or, by a currently unknown mechanism, regulation of calcium deposition in soft tissues (ABCC6).

Based on evolutionary homology, a large number of membrane transporters are grouped as solute carrier (SLC) proteins, and this huge group includes ion-coupled transporters, exchangers and so-called passive transporters, among others. The SLC nomenclature has been recently reviewed [26] and an extensive database is now provided [102] This database includes 52 gene families, altogether representing almost 400 different human SLC transporter genes. Interestingly, even within one SLC family, proteins with different mechanisms of actions (cotransporter, exchanger or facilitated transporter) can be found.

Surveying some of the most relevant SLC groups as potential biomarkers, the SLC1A1-7 proteins include $\mathrm{Na}$-dependent high-affinity glutamate and neutral amino acid transporters, 
involved in neurodegenerative diseases. The SLC2A1-14 proteins are facilitated glucose or other sugar/anion transporters, some of which (SLC2A1-4 [GLUT1-4]) have important alterations in diabetes and in other metabolic diseases, while the SLCA9-URAT1 protein is a transporter for uric acid secretion in the kidney. The SLC4 family includes various plasma membrane bicarbonate transporters, while the members of the SLC5 group are involved in Na-dependent small-molecule transport (e.g., glucose, choline or fatty acids). Interestingly, SLC5A2 is an $\mathrm{Na}$ dependent glucose transporter, with a key responsibility in renal glucose reabsorption, and a target of new antidiabetic agents.

The SLC6A1-20 proteins have a major role in plasma membrane neurotransmitter transport (mostly in the reuptake of GABA, L-3,4-dihydroxyphenylalanine, glycine etc.), while the proteins in the SLC17 and SLC18 families are responsible for vesicular neurotransmitter transport. Various groups are involved in the transport of, for example, bile salts (SLC10), urea (SLC14), folates (SLC19 and SLC46), larger organic anions (SLC21) and cations (SLC22), nucleosides (SLC29) or copper (SLC31). The numerous hereditary or acquired alterations in these proteins and the related diseases are extensively reviewed [102].

An important pharmacological aspect of the variations in membrane transporters is their contribution to the general ADME-Tox properties of numerous clinically applied drugs. Transporters are working in concert with drug-metabolizing enzymes and, thus, are key determinants of therapeutic and adverse drug responses. The key drug transporters are members of the ABC transporter family (see above) and some SLC transporter families. The latter mostly belong to the SLC22 group, which include both anionic (OATs) and cationic drug transporters (OCTs and OCTNs), and the SLCO (formerly SLC21) family (e.g., OATP1B1). A detailed discussion of the role of these transporters in drug application and development is provided in recent extensive reviews $[27,28]$.

\section{Structural proteins}

Structural protein components of cellular membranes include various cytoskeletal proteins, integrins, numerous members of the immunoglobulin superfamily and other proteins modulating cell-cell interactions. The cytoskeletal proteins stabilize a variety of protein-protein or proteinlipid interactions in the cell membranes, and their disorders in red blood cells (RBCs; erythrocyes) result in hemolytic diseases, while the malfunctioning of the major muscle cytoskeletal protein, dystrophin, causes syndromes of muscular dystrophy [29,30].

In most cases, these structural proteins with major extracellular parts are glycoproteins, including the so-called selectins; that is, lectintype domain-containing proteins, which modulate a variety of immune responses. Plasma membrane glycoproteins provide the basis for most blood group antigens, and act as virus receptors or even as tumor metastasis-promoting structures. Disorders of membrane glycosylation (e.g., the carbohydrate-deficient glycoprotein syndrome) affect numerous cellular functions, while the normal CD55 and CD59, glycosylphosphatidylinositol-anchored membrane proteins protect the cell membranes against complement attack [31-33].

Integral membrane glycoproteins, so-called integrins, provide the connections of the cell membranes with the extracellular matrix proteins, for example, collagen, laminin or elastin. The membrane integrins are dimers, composed of various combinations of $\alpha$ - and $\beta$-chains, and modulate cell migration, adhesion or even proliferation. Complexes of ITGAL, ITGAM and ITGAX on the leukocytes are involved in the prevention of bacterial and fungal infections; the GPIIb-IIIa integrin complex plays a key role in platelet activation. In addition to their structural role, integrins also provide a communication between the extracellular surface and the intracellular-binding proteins, and may serve to promote targeted delivery of pharmacological agents [34-36]. While these proteins have dedicated functions in selected cell types, human RBCs also express several adhesion molecules, including CD44 (HA receptor, Indian blood group), CD47 (MER6), CD50 (ICAM-3), CD58 (LFA-3) and CD242 (ICAM4, Landsteiner-Wiener blood group; see section 'Role of CD markers in diagnostics'). Integrin proteins have been shown to play a role in cancer drug resistance, probably by protecting against drug-induced apoptosis, providing a survival advantage. Thus, integrins may serve as predictive biomarkers in cancer therapy [37,38].

The close contacts in some cell layers are provided by the integral membrane tight junction proteins (e.g., the claudins or Zo1). The gap junction proteins or connexins provide a dynamic interaction between polarized cells and regulate signal transduction and transport processes. In the Schwann cells of the nervous system, gap junction proteins provide the cellular contacts to myelin sheets, and hydrophobic membrane 
proteins provide the key constituents of the myelin $[39,40]$.

\section{Membrane-bound enzymes}

Membrane-bound enzyme systems are important components of cellular defense mechanisms and metabolic regulation. As an example, the NADPH oxidase complex in the granulocyte membrane provides free radical production, allowing the killing of infectious bacteria, and the very serious chronic granulomatous disease develops in the absence of proper function of this enzyme [41].

Membrane endocytosis and exocytosis are complex membrane transport processes for large soluble or membrane proteins, as well as for other intracellular components. Receptor-dependent endocytosis is involved in the uptake of transferrin iron, or low-density lipoprotein cholesterol, while exocytotic vesicles allow rapid neurotransmitter release. The analysis of small exosomes with special membrane and intravesicular cargo recently also became a diagnostic possibility for specific membrane proteins [42].

The above, tentatively listed, membrane proteins responsible for receptor-dependent cellular responses, corresponding to various diseases, and modifying drug sensitivity or ADME-Tox properties, show great individual variations. The exact determination of these variations, particularly at the protein level, should provide a new source of diagnostic biomarkers, advancing drug research, therapeutic approaches and, in general, personalized medicine.

\section{Expression of membrane proteins: from genes to function \& localization}

As diagnostic biomarkers, the expression of properly localized, functional cell membrane proteins may provide valuable information, while the determination of the relevant coding DNA alterations or mRNA expression levels may not correspond to these proteins. Membrane proteins undergo complex processing and trafficking before (or even during) their actual expression in the target cellular membranes (Figure 1). Mutations or single nucleotide polymorphisms (SNPs) in the genome, alternative promoter use, as well as miRNAs and epigenetic factors, among others, may significantly modulate translated proteins. There are numerous data for genetic polymorphisms and mutations potentially affecting membrane protein expression, but data are scarce for the actual protein expression levels in relevant tissues.

In addition to genetic and epigenetic regulation, in the case of membrane proteins, major additional steps may contribute to the modulation of their local expression and function. Translation of membrane proteins already occurs in a membrane environment, as the insertion of the hydrophobic domains of the native proteins into the endoplasmic reticulum membrane is required to avoid protein precipitation or degradation, and factors contributing to membrane insertion of polypeptide chains under formation involve complex machinery. Potential lipid modifications usually occur during the steps of synthesis and membrane insertion, or immediately following the generation of a membrane-inserted protein.

In the life of membrane proteins, the following steps involve intracellular 'traveling' (trafficking); always in a membrane environment, this involves moving from larger membranous sheets of the Golgi and trans-Golgi network to cargo membrane vesicles to specific target membranes [43]. During these steps, chemical modifications (phosphorylation, glycosylation, ubiquitination,

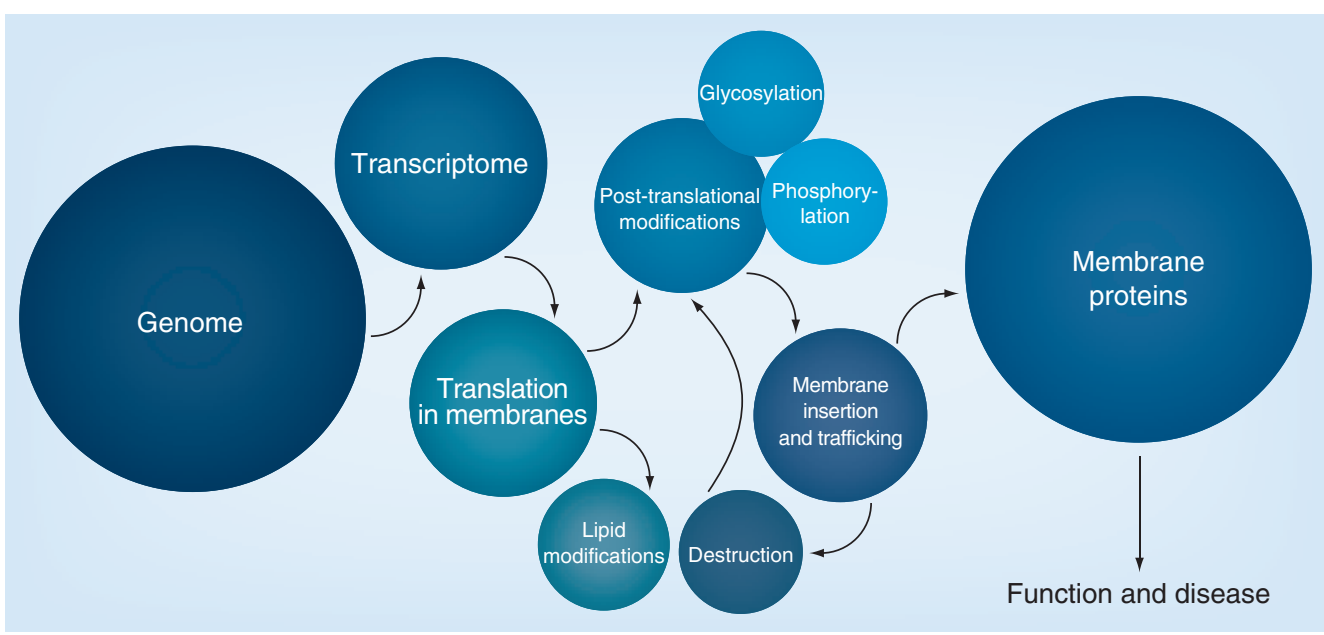

Figure 1. Processing of membrane proteins: from genes to localization and function. 
attachment of fatty acid chains etc.) also usually occur, and a quality control system assures the rapid removal and degradation of misfolded or misprocessed membrane proteins [44].

In polarized cells, where the apical and basolateral compartments contain significantly different components, a special trafficking and cargo system is involved in the proper targeting of membrane proteins. Relevant function of a membrane protein cannot be achieved if this targeting and processing is not fully controlled, and the misprocessed or mistargeted proteins result in major disease conditions. In the case of some large membrane proteins in polarized cells (e.g., the CFTR chloride channel protein or the SUR-Kir6.1 ATP-dependent potassium channel), most of the synthesized protein is degraded even under normal conditions, and if this degradation rate increases, no functional protein will reach the final membrane destination. Moreover, even after reaching a specific membrane compartment, many membrane proteins are continuously retrieved (mostly in the form of endocytotic vesicles), and either degraded or reinserted into the desired membrane compartment. Such membrane retrieval, especially if connected to a membrane protein receptor, or involved in ligand interactions, significantly alters the cellular response in a time- and condition-dependent manner [45].

A process already well recognized, but recently re-evaluated and appreciated, is the formation of cellular microvesicles. Such microvesicles may be the end products of cellular apoptosis, tumor cell membrane shedding, or may be physiological carriers of important messages between cells and tissue components. The small $(<0.1 \mu \mathrm{m})$ vesicles, called exosomes, were shown to contain only selected membrane proteins and carry DNA, RNA and, in particular, miRNA cargos [42].

Based on all these multiple modifications and processing of the membrane proteins, in general, mRNA levels do not correspond to their final expression level in the target membrane. Moreover, in many cases, neither mRNA nor final protein levels can be properly quantitated in human tissue samples, due to difficulties in obtaining and processing the most relevant human tissues. Thus, a direct determination of membrane protein biomarkers would greatly facilitate medical diagnostic and therapeutic potential.

Regarding the potential methods of quantitative membrane protein determinations, tandem mass spectrometry (MS/MS), in combination with liquid chromatography-MS/MS has recently been extensively developed. With this technology, by using appropriate standards and controlled procedures, a large number of membrane-spanning proteins, including receptors and transporters, became easily measurable $[46,47]$. In spite of promising new data, the relatively low abundance and the inaccessibility of the hydrophobic regions of the membrane proteins to proteolysis hampers this type of proteomic analysis, especially in a quantitative diagnostic approach [48]. The high cost, which results in the centralized application of the relevant MSbased instrumentation, is also a major problem in clinical diagnostics.

Antibody-based methods are widely used and would even allow point-of-care membrane protein clinical diagnostics, but also have major uncertainties. Again, the relatively low level and inaccessibility of many membrane proteins and the lack of appropriate reagents make this approach uncertain. Western blot technology, allowing direct identification of the detected proteins, is labor intensive and hard to quantitate; ELISA or other multiple antibody-based methods are highly efficient, but need extensive validation, and tissue immunostaining technologies require special expertise, instrumentation and, in most cases, are not quantitative. In the case of antibody-based technologies, the most widely used and accessible diagnostic method is the application of flow cytometry, which provided the basis of the cell surface marker (cluster of differentiation [CD]) evaluation technologies.

\section{Role of CD markers in diagnostics}

An important step in identifying cell membrane-based biomarkers was the development of the CD system. The CD identification of cell surface markers is based on the immunophenotyping of various cell types; that is, the recognition of specific cellular markers by antibodies developed in various laboratories. In the early 1980s the Human Leukocyte Differentiation Antigens Workshop was organized to validate the pre-existing leukocyte cell surface markers and to assign CD designations. The first $15 \mathrm{CD}$ molecules were validated on the 1st International Workshop and Conference on Human Leukocyte Differentiation Antigens in Paris in 1982 [49]. This validation process included multilaboratory analyses of antibodies raised against different cell types; therefore, CD antibodies became reliable tools to identify cell types by hematologists and immunologists around the world. This was necessary because nomenclature based on protein family homologs were constantly changing and molecules that proved to be present on the cell surface, but were not known to have a function, 
were posing a major problem for identification. In addition, different laboratories were using various nomenclatures, thus one cell surface molecule had multiple names.

From 2004, the Human Leukocyte Differentiation Antigens Workshop was followed by a series of Human Cell Differentiation Molecules Workshops in order to assign a CD nomenclature to nonleukocyte-specific antibodies and cellular markers as well [50]. To date, approximately 500 CD markers have been identified, but a full classification is still missing [51,52]. These hundreds of molecules, expressed on the cell surface, clearly play an essential role in cell function, differentiation and activation (FIGUre 2). Major databases, providing detailed information on the CD markers, are available [103,104].

The CD markers are mostly transmembrane proteins or glycoproteins, modified or glycosylated lipids, or in some cases only carbohydrates, identified on the cell surface. By now, CD markers representing hidden, probably intracellular epitopes, have also been added. In the CD system, + or - symbols indicate whether a CD molecule is expressed. The quantity of the distinct molecular markers are noted as high, mid or low. Molecules that are not well characterized, are marked with a 'w' in their CD specification.

CD markers are commonly used to define specific cell types, including stem cells, differentiated progenies, as well as various tumor cell types (Figure 3). The advantage of using this system is that $\mathrm{CD}$ markers can be recognized by specific monoclonal antibodies, generated against the epitopes on the cell surface, and this identification can be routinely used by clinical laboratories to diagnose many human diseases based on immunophenotyping. The CD marker molecules have been identified as playing critical roles in the regulation of immune response, mediation of cell adhesion or other interactions between cells, cell activation, proliferation and differentiation. Furthermore, some CD markers are responsible for the mediation and migration of hemopoietic cells, while some of them represent cellular inflammatory molecules, participating in signaling cascades. CD markers may represent virus receptors

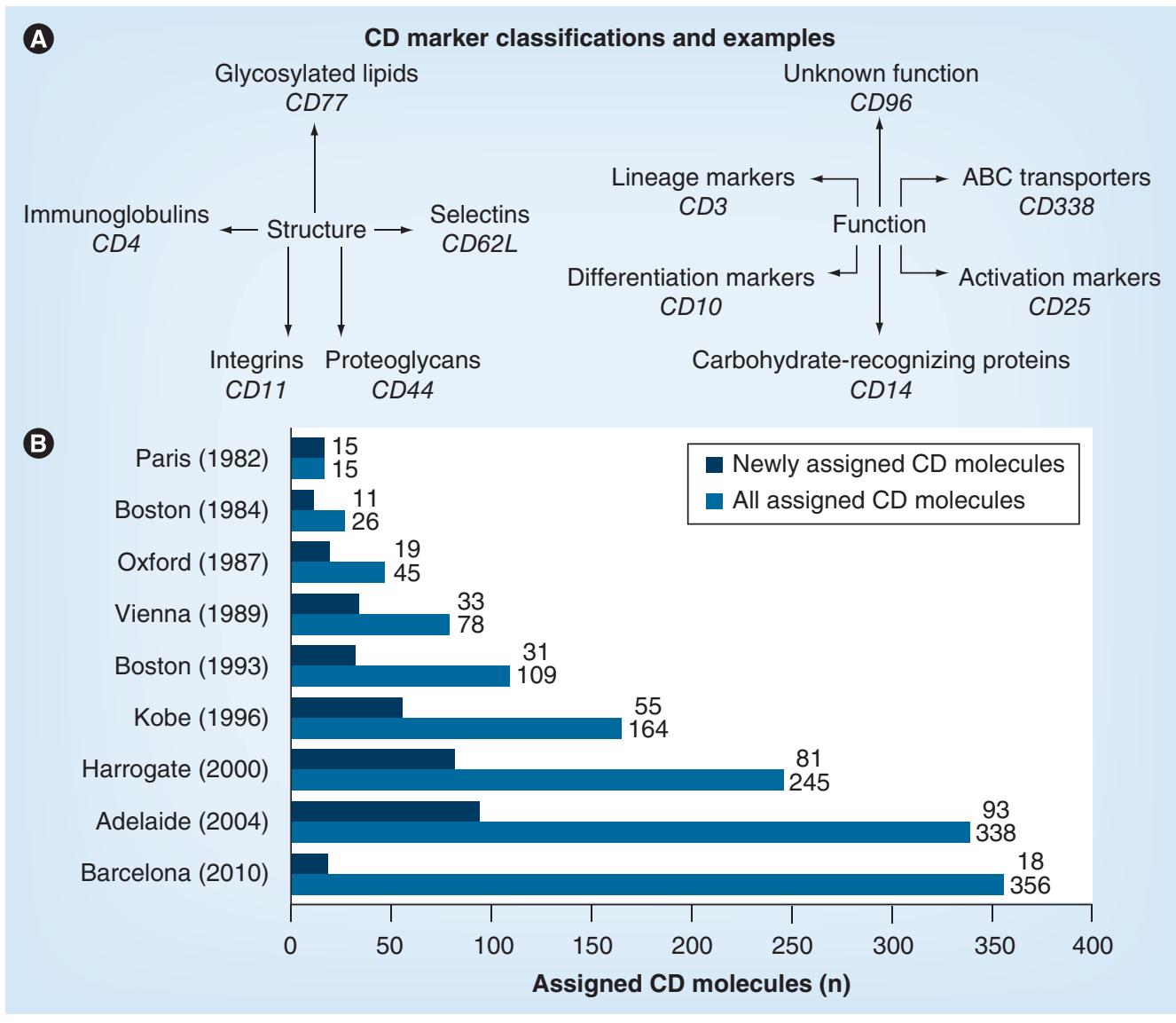

Figure 2. Numbers and types of cluster of differentiation markers. (A) Classification of cluster of differentiation molecules by structure or function. (B) Number of assigned CD molecules by the Human Cell Differentiation Molecules Workshop during the past 30 years (based on [44]). CD: Cluster of differentiation. 


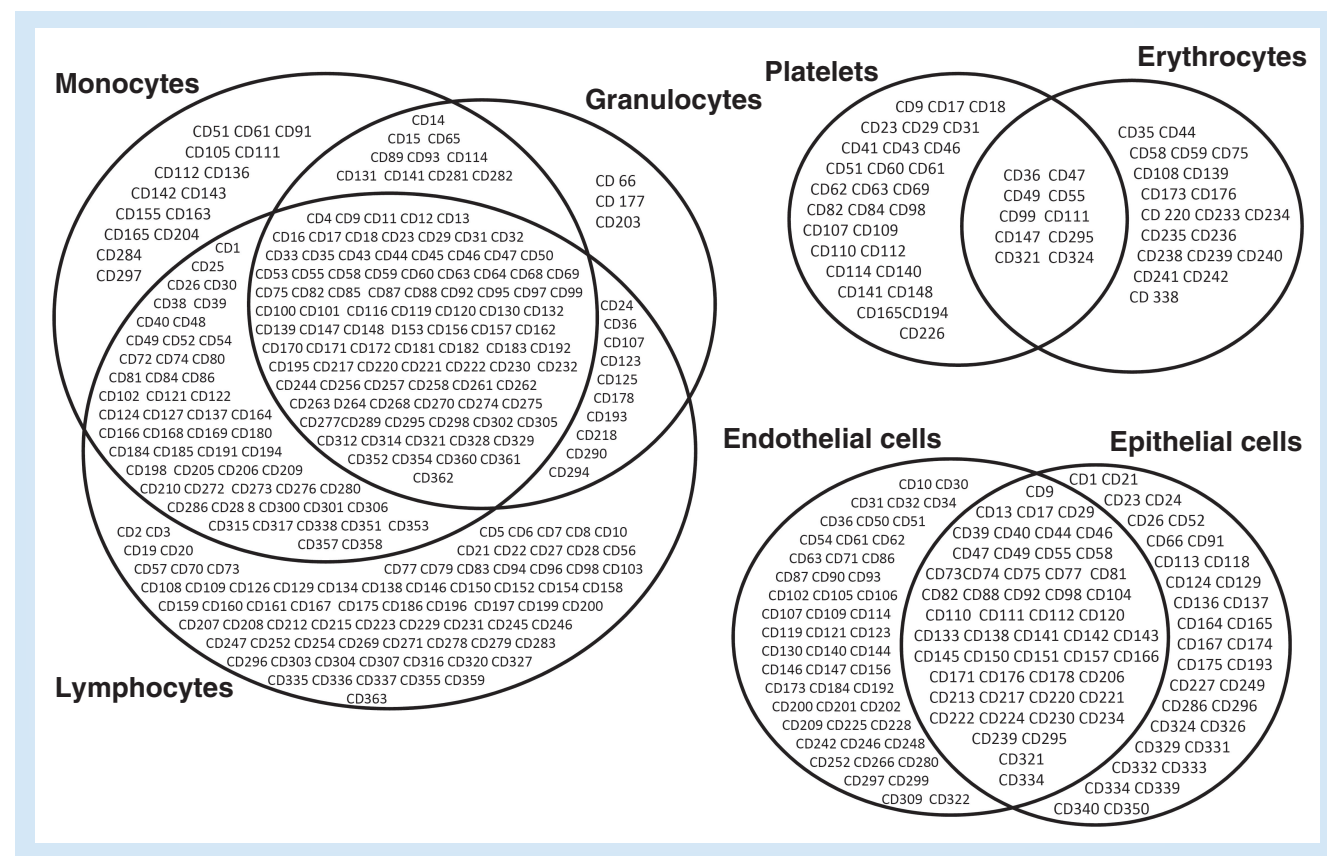

Figure 3. Occurrence of cluster of differentiation markers in different cell types.

and altered CD marker expression may identify diseased cell types [53]. Accordingly, CD markers are widely used as both prognostic and predicative markers in immunology or oncology/hematology [54] and, more recently, also in detecting potential cancer stem cells [55]. Some CD markers against monoclonal antibodies are already in clinical trials or at the clinic, thus these CDs are used as combined diagnostic markers, and therapeutic targets ('theranostic' biomarkers) are listed in Table 1.

The major advantage of the use of the CD marker system is that, even without knowing the actual molecular identity or function of a given marker, this specific labeling and the related

\section{Table 1. Examples of cluster of differentiation marker cell surface antigens that also serve as therapeutic} targets ('theranostic' biomarkers) according to the clinical application of specific monoclonal antibodies.

\begin{tabular}{|c|c|c|}
\hline $\begin{array}{l}\text { Biomarkers providing } \\
\text { therapeutic targets } \\
\text { ('theranostic' markers) }\end{array}$ & Disease & Examples of therapeutic antibody \\
\hline CD3 and variants & Autoimmune diseases, transplant rejection & $\begin{array}{l}\text { OKT3 (muromonab), otelixizumab, catumaxomab, foralumab, } \\
\text { visilizumab }\end{array}$ \\
\hline CD4 & Psoriasis, HIV, autoimmune diseases & Ibalizumab, cedelizumab, clenoliximab, keliximab, priliximab \\
\hline CD6 & Autoimmune diseases, Sjögren's syndrome & ALD518, itolizumab \\
\hline CD11a & Psoriasis, autoimmune diseases & Efalizumab \\
\hline CD19 & Lymphomas & Blinatumomab, taplitumomab \\
\hline CD20 & Lymphomas, autoimmune diseases & $\begin{array}{l}\text { Rituximab, afutuzumab, ibritumomab tiuxetan, ocaratuzumab, } \\
\text { ocrelizumab, ofatumumab, tositumomab }\end{array}$ \\
\hline CD22 & Lymphomas & Bectumomab, epratuzumab \\
\hline CD25 & T-cell depleting in transplantation & Basiliximab, daclizumab, inolimomab \\
\hline CD33 & Acute myeloid leukemia & Gemtuzumab ozogamicin \\
\hline CD52 & Leukemia & Alemtuzumab \\
\hline CD75 & Multiple myeloma & Milatuzumab \\
\hline CD125 & Asthma & Benralizumab \\
\hline CD340 & HER $2^{+}$cancer & Herceptin ${ }^{\circledR}$ (trastuzumab) \\
\hline
\end{tabular}


experience provides important information for clinicians or researchers regarding expected cellular behavior or disease progression. A major drawback of the CD system is that its database includes only molecular moieties that are recognized by the available antibodies (CD acceptance requires recognition by two independent monoclonal antibodies). In many cases, large, integral membrane proteins, including transporter or ion channels, while certainly present in most cellular membranes (e.g., $\alpha$-subunit of the $\mathrm{Na}-\mathrm{K}$ pump, calcium pump or MRP1 multidrug transporter) are not represented in the CD system, because the extracellular peptide portions are relatively small and/or the glycosylation patterns are not specific for a given protein or cell type. The blood group systems, including RBC antigens, have also been included into the $\mathrm{CD}$ nomenclature, but the nomenclatures and molecular identifications are still not fully clarified and updated.

Of course, the increasing understanding of the actual molecular background of a CD marker, identification of the protein background, and specific glycosylated lipids or proteins attached to carbohydrate molecules bring the CD system in close connection with genetic and protein databases. However, a unifying step in this regard, providing generally applicable combination databases, is still missing.

Since structural alterations of CD molecules may influence their expression levels, several methods have been developed to measure these quantitative changes. Flow cytometry has an especially broad application in this regard, and also allows the separation of different cell populations or subpopulations labeled by CD-reactive antibodies. For example, the relative abundance of $\mathrm{CD}^{+}{ }^{+}$and $\mathrm{CD}^{+}{ }^{+} \mathrm{T}$ cells is often used to monitor the progression of HIV infection, or the measurement of increased $\mathrm{CD} 4{ }^{+} \mathrm{CD} 15^{+} \mathrm{CD} 127^{\text {low }}$ regulatory $\mathrm{T}$ cell percentage may represent a reliable marker for observing lymphocyte dysfunctions in patients [56]. Identification of CD markers has an important role in the evaluation of progression of tumor growth or metastasis, and characterization of cancer stem cells based on CD markers may help to improve the effectiveness of targeted therapies against cancer [57].

CD markers are not only used for defining diseases, but also as therapeutic targets ('theranostic biomarkers'). As an example, a specific monoclonal antibody, rituximab, reacts with the CD20 molecule present on developing B cells and in particular on lymphoma B cells. CD20 belongs to the membrane-spanning $4 \mathrm{~A}$ protein coding gene family, with a still unknown specific function, but since the CD20-reactive rituximab destroys lymphoma cells, this was the first antibody-based agent used for B-cell depletion in lymphoma therapies. Moreover, rituximab has also become widely used in rheumatoid arthritis and in preventing graft rejection [58-60].

\section{Genetics \& environment: SNPs, mutations, regulation \& processing alterations of membrane proteins}

According to the above described general notions, genetic alterations may not directly correspond to changes in membrane protein expression and function. Still, in numerous cases, the exploration of the genetic background led to the discovery of membrane protein-related diseases. A famous example in this regard is the discovery of the molecular basis of the relatively frequent, and still lethal, heritable disease, cystic fibrosis.

Based on the disease phenotype, a genomewide search of 'reverse genetics' led to the discovery of a key mutation in the CFTR (ABCC7) gene, which, in approximately $60-70 \%$ of cases, is directly responsible for the alterations in the respective $\mathrm{ABCC} 7$ chloride channel and the development of the disease. However, to date, more than a thousand other disease-related mutations were also found in this gene. Moreover, another specific mutation in the same gene was found to be responsible for the congenital bilateral absence of the vas deferens, resulting in male infertility [61].

Many examples of these kind of monogenic, but relatively rare, membrane protein-related heritable diseases, caused by well-defined mutations, have already been mentioned in the previous sections. In Table 2 , we provide a somewhat more detailed (of course, still incomplete) list of such disorders and list the reviews and database sources for more information.

Among the monogenic membrane receptor diseases, mutations in growth factor receptors, calcium receptors, growth hormones, insulin, cytokines or cannabinoid receptor genes are well described. Mutations in GPCR genes are summarized in [105]. Heritable channelopathies are important causes of various forms of cardiac arrhythmia. Diseases based on mutations in various structural membrane proteins are often caused by improper glycosylation, but also include some forms of RBC destruction and muscular dystrophy. Lack of functional cell surface integrins causes adhesion deficiency in neutrophils and macrophages, disorders of platelet aggregation, severe skin diseases, complex forms of muscle and sensory problems, including deafness. Mutations 
Table 2. Examples of monogenic heritable diseases caused by mutations in genes coding for cell surface membrane proteins.

\begin{tabular}{|c|c|c|}
\hline $\begin{array}{l}\text { Membrane } \\
\text { proteins }\end{array}$ & Mutated proteins/genes & Diseases \\
\hline \multirow{11}{*}{$\begin{array}{l}\text { Membrane } \\
\text { receptors }\end{array}$} & \multirow[t]{2}{*}{ FGF receptors: FGFR1, FGFR2 } & Pfeiffer syndrome (early osteocalcification) \\
\hline & & Kallman syndrome (delayed or absent puberty and an impaired sense of smell) \\
\hline & FGFR3 & Muenke syndrome (complex developmental disease) \\
\hline & Calcium-sensing receptor & Neonatal severe hyperparathyroidism \\
\hline & Growth hormone receptor & Laron-type dwarfism \\
\hline & \multirow[t]{2}{*}{ INSR } & Donohue syndrome, leprechaunism (nonfunctional INSR) \\
\hline & & Mendenhall syndrome (less severe for insulin-resistant diabetes) \\
\hline & Bone morphogenic protein receptor & Primary pulmonary hypertension type 2 \\
\hline & Cytokine receptor: IL2R $\gamma$ & X-linked severe combined immunodeficiency \\
\hline & G-protein-coupled receptor & Color vision deficiency \\
\hline & Cannabinoid receptor & Neurodegenerative diseases \\
\hline \multirow[t]{4}{*}{ Ion channels } & KCNE1, KCNQ1 & Jervell and Lange-Nielsen syndrome \\
\hline & KCNE1, KCNE2, KCNH2, KCNQ1 & Romano-Ward syndrome (long QT syndrome) \\
\hline & SCN5A & Cardiac arrhythmia, idiopathic ventricular fibrillation \\
\hline & CACNA1C & Thimoty syndrome (cardiac long QT syndrome) \\
\hline \multirow{5}{*}{$\begin{array}{l}\text { ATP-dependent } \\
\text { membrane } \\
\text { transporters }\end{array}$} & Mg transporter: ATP1G1 & Autosomal dominant Mg-loss syndrome \\
\hline & $\mathrm{Na}-\mathrm{K}$ transporter: ATP1A2 & Familial hemiplegic migraine \\
\hline & Calcium transporter: ATP2B2 & Nonsyndromic deafness \\
\hline & Copper transporter: ATP7A & Menkes disease (copper metabolism) \\
\hline & Calcium transporter: ATP2A2 & Darier disease (desmosome-keratin filament complex abnormality) \\
\hline \multirow{13}{*}{$\begin{array}{l}\mathrm{ABC} \\
\text { transporters }\end{array}$} & ABCA1 & Tangier disease (familial $\alpha$-lipoprotein deficiency) \\
\hline & $A B C A 3$ & Surfactant metabolism dysfunction \\
\hline & $\mathrm{ABCA4}$ & Stargardt syndrome, retinitis pigmentosa \\
\hline & $\mathrm{ABCB} 3$ & Bare lymphocyte syndrome, immunodeficiency \\
\hline & $\mathrm{ABCB} 4$ & Intrahepatic cholestasis type 3 \\
\hline & $A B C B 7$ & Syderoblastic anemia with ataxia \\
\hline & $\mathrm{ABCB} 11$ & Intrahepatic cholestasis type 2 \\
\hline & $\mathrm{ABCC} 2$ & Dubin-Johnson syndrome (direct bilirubin accumulation) \\
\hline & ABCC6 & $\begin{array}{l}\text { Pseudoxanthoma elasticum (fragmentation and mineralization of elastic fibers in } \\
\text { some tissues) }\end{array}$ \\
\hline & $\mathrm{ABCC} 7$ & Cystic fibrosis, male sterility \\
\hline & $\mathrm{ABCC} 8$ & Persistent hyperinsulinemia of infancy \\
\hline & $A B C D 1$ & Adrenoleukodystrophy (disorder of peroxisomal fatty acid $\beta$-oxidation) \\
\hline & $A B C G 5, A B C G 7$ & Sitosterolemia \\
\hline \multirow{7}{*}{$\begin{array}{l}\text { SLC } \\
\text { transporters }\end{array}$} & SLC2A1 & Glut-1 deficiency syndrome (De Vivo disease) \\
\hline & $\mathrm{SLC} 2 \mathrm{~A} 2$ & Fanconi-Biskel syndrome (uncontrolled glucose levels) \\
\hline & SLC2A9 & Renal hypouricemia \\
\hline & SLC12A1 & Type I Bartter syndrome ( $\mathrm{Na}, \mathrm{K}$ and $\mathrm{Cl}$ cotransporter deficiency) \\
\hline & SLC12A3 & Gitelman syndrome (kidney-based cation imbalance) \\
\hline & SLC16A1 & Hyperinsulinemic hypoglycemia type 7 \\
\hline & SLC16A2 & Allan-Herndon-Dudley syndrome \\
\hline
\end{tabular}




\begin{tabular}{|c|c|c|}
\hline $\begin{array}{l}\text { Membrane } \\
\text { proteins }\end{array}$ & Mutated proteins/genes & Diseases \\
\hline \multirow{4}{*}{$\begin{array}{l}\text { SLC } \\
\text { transporters } \\
\text { (cont.) }\end{array}$} & SLC26A2 & Diastorphic dysplasia \\
\hline & SLC26A4 & Pendred syndrome \\
\hline & SLC40A1 & Hemochromatosis \\
\hline & SLC34A2 & Pulmonary alveolar microlithiasis \\
\hline \multirow{10}{*}{$\begin{array}{l}\text { Structural } \\
\text { membrane } \\
\text { proteins }\end{array}$} & PMM2 (CDG-la) & Carbohydrate-deficient glycoprotein syndrome \\
\hline & PIG-A & Paroxismal nocturnal hemoglobinuria \\
\hline & $D M D$ & Duchenne and Becke-type muscular dystrophy \\
\hline & $\begin{array}{l}\text { Functional cell surface integrins in } \\
\text { neutrophils and macrophages }\end{array}$ & Leukocyte adhesion deficiency type 1 \\
\hline & GPIIb-IIla complex & Glanzmann thrombastenia \\
\hline & Cytokeratins: KRT5, KRT14 & Epidermolysis bullosa \\
\hline & Connexin: GJB1 & Charcot-Marie-Tooth disease \\
\hline & Connexin: GJB2 & Nonsyndromic deafness \\
\hline & Proteolipid protein: PLP1 & Pelizaeus-Merzbacher disease \\
\hline & Glypican: GPC3 & Simpson-Golabi-Behmel-type growth disorder \\
\hline
\end{tabular}

that affect the structure and formation of myelin cause disorders of the CNS.

Disease-causing mutations in various ATPdependent membrane transporter proteins are detailed in [106]. As examples, these include metabolic diseases, migraine, nonsyndromic deafness, copper transport-related syndromes, as well as skin diseases. The numerous ABC transporterrelated genetic disorders include metabolic and lipid disorders, eye diseases, hematological and immunological problems, as well as skin diseases $[20,24]$. The monogenic hereditary diseases caused by mutations in SLC transporters also include a wide variety of seemingly unrelated conditions [107]. In particular, metabolic, liver-, kidneyand brain-related diseases are linked to these transporters.

In many cases, even in these monogenic diseases, the time-dependent development and/or the severity of the disease phenotypes are significantly affected by epigenetic and environmental factors (Figures $1 \& 4$ ). This is even more relevant in the cases of complex, multigenic diseases, in which the polymorphic variants of membrane proteins are often participating factors. In these cases, only huge genome-wide association studies (GWAS) allowed the recognition of the significance of genetic factors in disease development $[62,63]$.

There are numerous examples of the association of membrane protein polymorphisms with complex disease conditions. Examples are the GWAS indicating the association of hypertension and blood pressure salt sensitivity with SNPs in genes coding for the angiotensin II receptor, $\beta$-receptors and epithelial $\mathrm{Na}$ channel genes, and the regulation of the $\mathrm{Na}-\mathrm{K}$ ATPase by $\alpha$-adducin [64]. In addition, the association of the development of Parkinson's disease with SNP-modifying glutamate receptor activity, $\mathrm{O}$-glycan biosynthesis, ligand-gated ion channel activity and GABA receptor activity has been suggested $[65,66]$. In Alzheimer's disease, lipid disorders connected to alteration in the $A B C A 7$ transporter gene function were found to be significant factors [67].

An interesting example of the role of membrane transporters in diseases is a GWAS exploring the molecular genetic background of gout [68]. In this study, the key SNPs were found in four transporter genes: one $\mathrm{ABC}$ transporter $(A B C G 2)$ and three SLC-type transporters (SLC2A9, SLC22A12 [URAT1] and SLC17A1). Detailed examination of the SNP in $A B C G 2$, coding for a frequently observed Q $141 \mathrm{~K}$ polymorphism, showed impaired protein trafficking (and possibly function), and actually led to the discovery of the uric acid transport capacity of ABCG2 [69].

In the application of widely used medicines, GWAS may be important methodologies to find interactions between the personal genetic background and drug side effects. A major GWAS scan found a single strong association of 


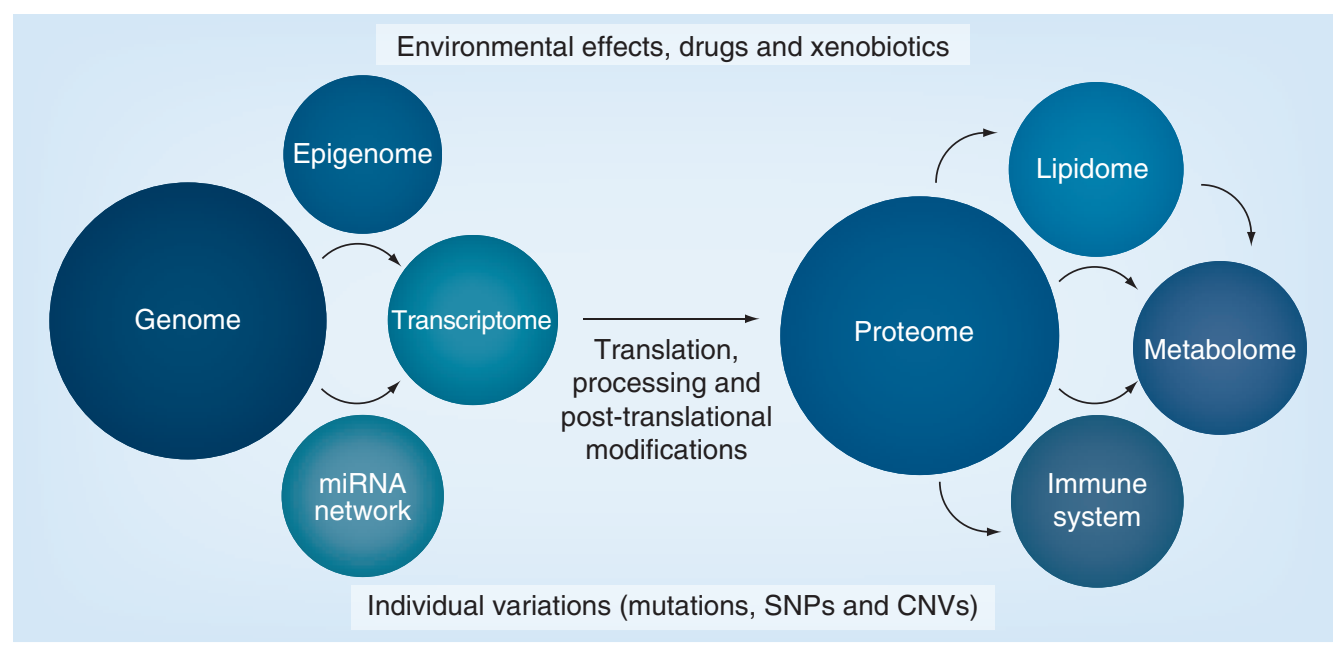

Figure 4. Factors and interactions affecting membrane protein expression at the individual level.

CNV: Copy number variation; SNP: Single nucleoide polymorphism.

statin-induced myopathy with an SNP located within the SLCOIB1 gene [70]. As mentioned previously, SLCO1B1 encodes the organic aniontransporting polypeptide OATP1B1, which has been shown to regulate the hepatic uptake of statins. Since major clinical studies reinforced a close correlation of this polymorphism in myopathy with simvastatin application [71], genotyping of this variant may help to achieve the benefits of statin therapy more safely and effectively.

Regarding the role of transporters in various complex diseases, variations in certain $\mathrm{ABC}$ transporters (BSEP and ABCB11) and the SLCtype transporters were found to be implicated in cholelithiasis [72]. A significant role of SNPs in the SLC10A2 gene, coding for a bile salt transporter in gall stone formation, in a wide range of subjects has been suggested. A recent GWAS in bladder cancer patients found a new susceptibility locus within SLC14A1, a urea transporter gene [73].

It has to be emphasized that in all these conditions, the genetic association of an SNP/protein polymorphism is only a statistical indicator for potential disease development. A major problem with these genetic associations is that the final membrane protein expression level is the result of multiple cellular (genetic and environmental) interactions (Figure 4). Thus, the direct detection of actual protein expression and function may become a key personalized biomarker in these diseases.

\section{RBC membrane proteins as potential biomarkers}

It has been demonstrated that human erythrocytes (RBCs) express numerous membrane proteins, including transporters and receptors, in their single plasma membrane [74,75]. The easy availability of blood samples and the potential reflection of tissue-specific membrane protein expression in the RBC membrane make this platform feasible for simple and rapid quantitative biomarker reporter assays. According to currently available information on the RBC membrane proteome, numerous membrane proteins with known involvement in human diseases, and thought to be characteristic for special organs and tissues, are expressed in measurable quantities in the RBC membrane [74,76].

Various techniques have already been applied to measure the function and/or expression of $\mathrm{RBC}$ membrane proteins related to disease conditions. $\mathrm{RBC} \mathrm{Na}-\mathrm{Li}$ and $\mathrm{Na}-\mathrm{H}$ countertransport activity was found to predict susceptibility to diabetes and hypertension [77,78]. Among many examples, Sprague et al., assessing protein expression levels by western blot analysis, reported that the expression of the heterotrimeric G-protein $G_{i}$ is selectively decreased in RBCs of Type 2 diabetes patients [79]. Antonelou $e t$ al. identified secretory CLU (sCLU), a chaperone that has been implicated in several pathological conditions, as a component attached to human RBCs [80]. The authors studied the erythrocytic membranebound sCLU by using a combination of molecular, biochemical and high-resolution microscopic methods. They concluded that reduced sCLU protein levels are sensitive biomarkers of senescence and cellular stress. However, all these studies used technologies (e.g., western blot, transport activity measurements and special microscopy techniques) that are only available in specialized research laboratories, and by using these technologies, it is inherently very difficult to quantify 
membrane protein expression. While recent liquid chromatography-MS/MS technologies are promising regarding quantitative membrane protein determination (see section 'Expression of membrane proteins: from genes to function $\&$ localization'), their diagnostic application at a clinical level is currently not available. Moreover, the current RBC protein databases provided by MS-based technologies are quite uncertain and hardly comparable, even in a qualitative description [81]. In some cases, flow cytometry was also used to detect RBC membrane proteins, but there was no attempt to offer a technology to quantitate this membrane protein expression.

We suggest that RBC membrane proteins offer a unique source for effective and simple biomarker diagnostic assays. Such an assay would require the development of an effective and fast technology to assess quantitative membrane protein expression levels in RBCs.

As published recently, we have developed a simple, rapid, reliable flow cytometry-based diagnostic assay for the quantitative determination of the membrane protein, $\mathrm{ABCG} 2$, in the $\mathrm{RBC}$ membrane [82]. By using specific antibodies, we could detect ABCG2 specifically and sensitively in RBCs. In order to quantitate ABCG2 expression levels, the calibration of antibody binding was performed and maximum labeling conditions were used to determine protein levels. Using this method we could detect significant ABCG2 levels varying within a limited range and we could exclude that differences in ABCG2 expression levels were caused by age or sex. However, when we checked these samples for the presence of the $A B C G 2 \mathrm{Q} 141 \mathrm{~K}$ polymorphic variant, most common among the Caucasian population, we found that the RBCs of the donors carrying a heterozygous $\mathrm{Q} 141 \mathrm{~K}$ variant had approximately $15 \%$ lower expression of ABCG2, as compared to homozygous wild-type donors. In addition, we found two donors showing much lower RBC ABCG2 expression ( $50 \%)$, although they did not carry the $\mathrm{Q} 141 \mathrm{~K}$ polymorphism. When we sequenced the $A B C G 2$ gene exons, we found that these (otherwise healthy) individuals had heterozygous mutations, resulting in premature termination of ABCG2 expression.

These data demonstrated a close correlation between $A B C G 2$ genotypes and the expression levels of the ABCG2 protein in the red blood cell membrane; moreover, they showed a biallelic expression pattern for the ABCG 2 protein, as suggested earlier, based on mRNA data [83]. Since ABCG 2 expression has been documented to affect uric acid transport-related conditions, for example, gout development, the direct determination of the ABCG2 levels in the RBC membrane may provide a simple and fast tool to characterize patients potentially developing hyperuricemia and becoming afflicted with gout. Additionally, as it was previously mentioned, determination of ABCG2 expression may have a predictive value in cancer drug treatment, in ADME-Tox, and is applicable for determining potential efficacy and/or toxicity of drug treatments in diseases.

Recently, we have further increased the panel of quantitative membrane protein detection in the RBC membrane, by examining several transporters and receptors through antibody binding in flow cytometry (Box 1). As an example, we have recently developed a quantitative assay for the expression of INSR in the RBCs [VARAdy G ET AL., Unpublished Data]. It has already been shown, decades ago, that human RBCs express functional INSR. Various techniques have been applied to determine the INSR function in RBCs, and a correlation was revealed between diabetes and, for example, insulin binding or insulin RTK activity $[84,85]$. However, no simple and fast, quantitative detection methods have been developed as yet for measuring INSR levels in RBCs. In our recently developed, flow cytometry-based method, after antibody titration and by using saturating amounts of selected antibodies, we could quantitate the RBC membrane INSR protein expression levels. By using this method, the level of the INSR protein in the human RBC membrane will be correlated with disease metrics

Box 1. Potential membrane protein
biomarkers in the human red blood cell
membrane: assays currently under
development.
Diabetes/metabolic disorders
- SLC2A1 (GLUT1)
- SLC2A3 (GLUT3)
- SLC2A2 (GLUT2)
- INSR (CD220)
- ABCG2 (CD338)
- SLC14A1 (Urea transporter, Kidd antigen)
- Flotillin
- ABCA1
- Phospholipid scramblase
Cancer drug resistance/drug metabolism
- ABCC1 (MRP1)
- ABCC4 (MRP4)
- ABCG2 (MXR, BCRP, CD338)
- ABCB6
- SLC2B1 (OATP2B1)


to determine whether erythrocytic INSR levels are predictors of the development and treatment response of diabetes and related conditions. Together with the easy accessibility of small amounts of human RBCs, these methods may provide a breakthrough in membrane protein biomarker diagnostics.

\section{Future perspective}

New biomarkers are essential in medical diagnostics and therapy, especially by serving as important tools in the development of personalized or stratified medicines. Already widely used medicinal products may reach new or more efficient and less harmful applications if the populations of patients with optimal response can be selected. Innovative new medicines may be developed for well-defined patient groups, based not only on phenotypic disease conditions but on a detailed characterization of personal biomarkers.

As described in this paper, membrane proteins may serve as important biomarkers in this regard, while the indirect determination of genetic or epigenetic modifiers may not reliably reflect the actual expression pattern of membrane proteins. At the same time, the direct determination of membrane proteins is significantly hindered by methodological and accessibility problems.

In this review, we suggest that recently developed RBC membrane markers could significantly contribute to diagnostic panels in numerous diseases affecting membrane proteins. In general, useful biomarkers should follow the simple rule of five [Walker J, Pers. Comm.]; that is, they should be:
- Relevant (closely connected to the phenotype or disease condition);

- Reliable (based on a well-established assay platform);

- Readily available (potentially as a 'point-ofcare' diagnostic, or at least performed at centralized medical diagnostic laboratories);

- Recognized (appreciated by healthcare professionals on the basis of already-known laboratory methods);

- Reimbursed (i.e., financially acceptable for health insurance or general healthcare providers).

Since the RBC membrane assay platforms conform to all these rules, quantitative determination of the RBC membrane proteins and the association of these quantitations with genetic markers, that is, mutations, SNPs, cellular regulatory alterations, epigenetic modulators and so on, may provide a highly applicable set of new biomarkers.

\section{Financial \& competing interests disclosure}

This work has been supported by a research grant from OTKA 83533 (B Sarkadi). The authors recently applied for a patent describing the technology of red blood cell biomarker assays. The authors have no other relevant affiliations or financial involvement with any organization or entity with a financial interest in or financial conflict with the subject matter or materials discussed in the manuscript apart from those disclosed.

No writing assistance was utilized in the production of this manuscript.

\section{Executive summary}

\section{Role of membrane proteins in health \& disease}

- Membrane proteins (receptors, channels, transporters, structural proteins and membrane enzymes) should serve as important diagnostic biomarkers, reflecting individual variations and thus allowing tailored therapeutic interventions.

- Owing to limited accessibility and technical difficulties, at present only a limited number of cell membrane proteins are applied as diagnostic biomarkers.

\section{Expression of membrane proteins: from genes to function \& localization}

- Because of secondary modifications, processing and trafficking variations, cellular mRNA expression, in most cases, does not reflect functional membrane protein levels.

- In order to provide valuable prognostic, predictive and theranostic biomarkers, cell surface membrane protein expression should be quantitatively determined.

\section{Role of the cluster of differentiation markers in diagnostics}

" In various diseases the determination of cluster of differentiation markers is successfully applied in medical diagnostics.

- Cluster of differentiation markers serve as valuable prognostic and predictive diagnostic tools.

\section{Red blood cell membrane proteins as potential biomarkers}

- In human red blood cells (erythrocytes), numerous cell membrane proteins are expressed and these expression levels correlate with the individual genetic background.

- Red blood cell membrane proteins may serve as relatively stable and easily accessible personalized biomarkers. 


\section{References}

Papers of special note have been highlighted as:

- of interest

" " of considerable interest

1 Lemmon MA, Schlessinger J. Cell signaling by receptor tyrosine kinases. Cell 141(7), 1117-1134 (2010).

III Key comprehensive review.

2 Xu AM, Huang PH. Receptor tyrosine kinase coactivation networks in cancer. Cancer Res. 70 (10), 3857-3860 (2010).

3 Traxler P. Tyrosine kinases as targets in cancer therapy - successes and failures. Expert Opin. Ther. Targets 7(2), 215-234 (2003).

4 Singleton KR, Kim J, Hinz TK et al. A receptor tyrosine kinase network composed of fibroblast growth factor receptors, epidermal growth factor receptor, v-erb-b2 erythroblastic leukemia viral oncogene homolog 2, and hepatocyte growth factor receptor drives growth and survival of head and neck squamous carcinoma cell lines. Mol. Pharmacol. 83(4), 882-893 (2013).

5 Arnold D, Peinert S, Voigt W, Schmoll HJ Epidermal growth factor receptor tyrosine kinase inhibitors: present and future role in gastrointestinal cancer treatment: a review. Oncologist 11(6), 602-611 (2006).

6 Joshi AD, Loilome W, Siu IM, Tyler B, Gallia GL, Riggins GJ. Evaluation of tyrosine kinase inhibitor combinations for glioblastoma therapy. PLoS ONE 7(10), e44372 (2012).

7 Lidgren $\mathrm{M}$, Wilking $\mathrm{N}$, Jonsson $\mathrm{B}$, Rehnberg C. Cost-effectiveness of HER2 testing and trastuzumab therapy for metastatic breast cancer. Acta Oncol. 47(6), 1018-1028 (2008).

8 Lundstrom K. An overview on GPCRs and drug discovery: structure-based drug design and structural biology on GPCRs. Methods Mol. Biol. 552, 51-66 (2009).

- Key comprehensive review.

9 Stevens RC, Cherezov V, Katritch V et al. The GPCR Network: a large-scale collaboration to determine human GPCR structure and function. Nat. Rev. Drug Discov. 12(1), 25-34 (2013).

"- Key comprehensive review.

10 Salon JA, Lodowski DT, Palczewski K. The significance of $\mathrm{G}$ protein-coupled receptor crystallography for drug discovery. Pharmacol. Rev. 63(4), 901-937 (2011).

11 Harrison C. Muddy waters for authorized generics. Nat. Rev. Drug Discov. 5(8), 624-625 (2006).

12 Congreve M, Marshall F. The impact of GPCR structures on pharmacology and structure-based drug design. Br. J. Pharmacol. 159(5), 986-996 (2010).
13 Catterall WA. From ionic currents to molecular mechanisms: the structure and function of voltage-gated sodium channels. Neuron 26(1), 13-25 (2000).

- Key original discovery or early review paper.

14 Kaupp UB, Seifert R. Cyclic nucleotide-gated ion channels. Physiol. Rev. 82(3), 769-824 (2002).

- Key original discovery or early review paper.

15 Keramidas A, Moorhouse AJ, Schofield PR, Barry PH. Ligand-gated ion channels: mechanisms underlying ion selectivity. Prog. Biophys. Mol. Biol. 86(2), 161-204 (2004).

16 Zamponi GW. Welcome to 'ion channels: key therapeutic targets'. Future Med. Chem. 2(5), 689-690 (2010).

17 Moss AJ, Kass RS. Long QT syndrome: from channels to cardiac arrhythmias. J. Clin. Invest. 115(8), 2018-2024 (2005).

18 Morita H, Wu J, Zipes DP. The QT syndromes: long and short. Lancet 372(9640), 750-763 (2008).

"1. Key comprehensive review.

19 Gottesman MM, Ambudkar SV. Overview: $A B C$ transporters and human disease. J. Bioenerg. Biomembr. 33(6), 453-458 (2001).

- Key original discovery or early review paper.

20 Dean M. The genetics of ATP-binding cassette transporters. Methods Enzymol. 400, 409-429 (2005).

21 Cooper MA. Advances in membrane receptor screening and analysis. J. Mol. Recognit. 17(4), 286-315 (2004).

" Key original discovery or early review paper.

22 De Meyts P. The insulin receptor: a prototype for dimeric, allosteric membrane receptors? Trends Biochem. Sci. 33(8), 376-384 (2008).

- Key original discovery or early review paper.

23 Palmgren MG, Nissen P. P-type ATPases. Annu. Rev. Biophys. 40, 243-266 (2011).

"- Key comprehensive review.

24 Borst P, Elferink RO. Mammalian ABC transporters in health and disease. Annu. Rev. Biochem. 71, 537-592 (2002).

25 Sarkadi B, Homolya L, Szakacs G, Varadi A. Human multidrug resistance $\mathrm{ABCB}$ and ABCG transporters: participation in a chemoimmunity defense system. Physiol. Rev. 86(4), 1179-1236 (2006).

"- Key comprehensive review.

26 Hediger MA, Clemencon B, Burrier RE, Bruford EA. The ABCs of membrane transporters in health and disease (SLC series): introduction. Mol. Aspects Med. 34(2-3), 95-107 (2013).

"w. Key comprehensive review.
27 Yee SW, Chen L, Giacomini KM. Pharmacogenomics of membrane transporters: past, present and future. Pharmacogenomics 11(4), 475-479 (2010).

- Key original discovery or early review paper.

28 Degorter MK, Xia CQ, Yang JJ, Kim RB. Drug transporters in drug efficacy and toxicity. Annu. Rev. Pharmacol. Toxicol. 52, 249-273 (2012).

- Key original discovery or early review paper.

29 Emery AE. The muscular dystrophies. Lancet 359(9307), 687-695 (2002).

30 Nowak KJ, Davies KE. Duchenne muscular dystrophy and dystrophin: pathogenesis and opportunities for treatment. EMBO Rep. 5(9), 872-876 (2004).

31 Jaeken J, Carchon H. Congenital disorders of glycosylation: a booming chapter of pediatrics. Curr. Opin. Pediatr. 16(4), 434-439 (2004).

32 Rosnoblet C, Peanne R, Legrand D, Foulquier F. Glycosylation disorders of membrane trafficking. Glycoconj. J. 30 (1), 23-31 (2013).

II Key comprehensive review.

33 Woods AG, Woods CW, Snow TM. Congenital disorders of glycosylation. $A d v$. Neonatal Care 12(2), 90-95 (2012).

34 Barczyk M, Carracedo S, Gullberg D. Integrins. Cell Tissue Res. 339(1), 269-280 (2010).

=- Key comprehensive review.

35 Kim C, Ye F, Ginsberg MH. Regulation of integrin activation. Annu. Rev. Cell Dev. Biol. 27, 321-345 (2011)

36 Millard M, Odde S, Neamati N. Integrin targeted therapeutics. Theranostics 1, 154-188 (2011).

- Key original discovery or early review paper.

37 Aoudjit F, Vuori K. Integrin signaling in cancer cell survival and chemoresistance. Chemother. Res. Pract. 2012, 283181 (2012).

38 Naci D, El Azreq MA, Chetoui N et al. $\alpha 2 \beta 1$ integrin promotes chemoresistance against doxorubicin in cancer cells through extracellular signal-regulated kinase (ERK). J. Biol. Chem. 287(21), 17065-17076 (2012).

39 Menichella DM, Goodenough DA, Sirkowski E, Scherer SS, Paul DL. Connexins are critical for normal myelination in the CNS. J. Neurosci. 23(13), 5963-5973 (2003).

40 Dbouk HA, Mroue RM, El-Sabban ME, Talhouk RS. Connexins: a myriad of functions extending beyond assembly of gap junction channels. Cell. Commun. Signal. 7, 4 (2009).

41 El-Benna J, Dang PM, Gougerot-Pocidalo MA, Marie JC, Braut-Boucher F. p47phox, the phagocyte NADPH oxidase/NOX2 organizer: structure, phosphorylation and implication in 
diseases. Exp. Mol. Med. 41(4), 217-225 (2009).

- Key original discovery or early review paper.

42 Vlassov AV, Magdaleno S, Setterquist R, Conrad R. Exosomes: current knowledge of their composition, biological functions, and diagnostic and therapeutic potentials. Biochim. Biophys. Acta 1820(7), 940-948 (2012).

43 Glick BS, Nakano A. Membrane traffic within the Golgi apparatus. Annu. Rev. Cell Dev. Biol. 25, 113-132 (2009).

44 MacGurn JA, Hsu PC, Emr SD. Ubiquitin and membrane protein turnover: from cradle to grave. Annu. Rev. Biochem. 81, 231-259 (2012).

- Key original discovery or early review paper.

45 Beguin P, Hasler U, Staub O, Geering K. Endoplasmic reticulum quality control of oligomeric membrane proteins: topogenic determinants involved in the degradation of the unassembled $\mathrm{Na}$,K-ATPase $\alpha$ subunit and in its stabilization by $\beta$ subunit assembly. Mol. Biol. Cell 11(5), 1657-1672 (2000).

- Key original discovery or early review paper.

46 Sakamoto A, Matsumaru T, Yamamura N et al. Quantitative expression of human drug transporter proteins in lung tissues: analysis of regional, gender, and interindividual differences by liquid chromatography-tandem mass spectrometry. J. Pharm. Sci. 102(9), 3395-3406 (2013)

47 Ohtsuki S, Ikeda C, Uchida Y et al. Quantitative targeted absolute proteomic analysis of transporters, receptors and junction proteins for validation of human cerebral microvascular endothelial cell line hCMEC/D3 as a human blood-brain barrier model. Mol. Pharm. 10(1), 289-296 (2013).

48 Lai X. Reproducible method to enrich membrane proteins with high purity and high yield for an LC-MS/MS approach in quantitative membrane proteomics. Electrophoresis 34(6), 809-817 (2013).

49 Bernard A, Brottier P, Georget E, Lepage V, Boumsell L. Joint report of the first international workshop on human leucocyte differentiation antigens by the investigators of the participating laboratories. In: Leucocyte Typing I. Bernard A et al. (Eds). Springer Verlag, Germany, 9-135 (1984).

50 Zola H, Swart B, Banham A et al. CD molecules 2006 - human cell differentiation molecules. J. Immunol. Methods 319(1-2), 1-5 (2007).

III Key comprehensive review.

51 Zola H, Swart B, Nicholson I et al. CD molecules 2005: human cell differentiation molecules. Blood 106(9), 3123-3126 (2005).
52 Zola H, Swart B. The human leucocyte differentiation antigens (HLDA) workshops: the evolving role of antibodies in research, diagnosis and therapy. Cell Res. 15(9), 691-694 (2005).

53 Broux B, Markovic-Plese S, Stinissen P, Hellings N. Pathogenic features of $\mathrm{CD} 4{ }^{+} \mathrm{CD} 28^{-} \mathrm{T}$ cells in immune disorders. Trends Mol. Med. 18(8), 446-453 (2012).

54 Parker TL, Strout MP. Chronic lymphocytic leukemia: prognostic factors and impact on treatment. Discov. Med. 11(57), 115-123 (2011).

55 Keysar SB, Jimeno A. More than markers: biological significance of cancer stem celldefining molecules. Mol. Cancer Ther. 9(9), 2450-2457 (2010).

56 Venet F, Lepape A, Monneret G. Clinical review: flow cytometry perspectives in the ICU - from diagnosis of infection to monitoring of injury-induced immune dysfunctions. Crit. Care 15(5), 231 (2011).

57 Schmitt F, Ricardo S, Vieira AF, Dionisio MR, Paredes J. Cancer stem cell markers in breast neoplasias: their relevance and distribution in distinct molecular subtypes. Virchows Arch. 460 (6), 545-553 (2012).

- Key original discovery or early review paper.

58 Leandro MJ, Becerra-Fernandez E. B-cell therapies in established rheumatoid arthritis. Best Pract. Res. Clin. Rheumatol. 25(4), 535-548 (2011).

59 Aggarwal A, Pyle J, Hamilton J, Bhat G. Low-dose rituximab therapy for antibodymediated rejection in a highly sensitized heart-transplant recipient. Tex. Heart Inst. J. 39(6), 901-905 (2012).

- Key original discovery or early review paper.

60 Cang S, Mukhi N, Wang K, Liu D. Novel CD20 monoclonal antibodies for lymphoma therapy. J. Hematol. Oncol. 5, 64 (2012).

- Key original discovery or early review paper.

61 Hanrahan JW, Tabcharani JA, Becq F et al. Function and dysfunction of the CFTR chloride channel. Soc. Gen. Physiol. Ser. 50, 125-137 (1995).

- Key original discovery or early review paper.

62 Mccarthy MI, Abecasis GR, Cardon LR et al. Genome-wide association studies for complex traits: consensus, uncertainty and challenges. Nat. Rev. Genet. 9(5), 356-369 (2008).

63 Stranger BE, Stahl EA, Raj T. Progress and promise of genome-wide association studies for human complex trait genetics. Genetics 187(2), 367-383 (2011).

-1- Key comprehensive review.

64 Kelly TN, He J. Gene-sodium interaction and blood pressure: findings from genomics research of blood pressure salt sensitivity.
Prog. Mol. Biol. Transl. Sci. 108, 237-260 (2012).

65 Maraganore DM, de Andrade M, Lesnick TG et al. High-resolution whole-genome association study of Parkinson disease. Am. J. Hum. Genet. 77(5), 685-693 (2005).

- Key original discovery or early review paper.

66 Fung HC, Scholz S, Matarin M et al. Genome-wide genotyping in Parkinson's disease and neurologically normal controls: first stage analysis and public release of data. Lancet Neurol. 5(11), 911-916 (2006).

67 Nussbaum RL. Genome-wide association studies, Alzheimer disease, and understudied populations. JAMA 309(14), 1527-1528 (2013).

68 Woodward OM, Kottgen A, Coresh J, Boerwinkle E, Guggino WB, Kottgen M. Identification of a urate transporter, ABCG2, with a common functional polymorphism causing gout. Proc. Natl Acad. Sci. USA 106(25), 10338-10342 (2009).

- Key original discovery or early review paper.

69 Basseville A, Bates SE. Gout, genetics and ABC transporters. F1000 Biol. Rep. 3, 23 (2011).

70 Group SC, Link E, Parish S et al. SLCO1B1 variants and statin-induced myopathy - a genomewide study. N. Engl. J. Med. 359(8), 789-799 (2008).

- Key original discovery or early review paper.

71 Wilke RA, Ramsey LB, Johnson SG et al. The clinical pharmacogenomics implementation consortium: CPIC guideline for SLCO1B1 and simvastatin-induced myopathy. Clin. Pharmacol. Ther. 92(1), 112-117 (2012).

72 Stokes CS, Lammert F. Transporters in cholelithiasis. Biol. Chem. 393(1-2), 3-10 (2012).

73 Garcia-Closas M, Ye Y, Rothman N et al. A genome-wide association study of bladder cancer identifies a new susceptibility locus within $S L C 14 A 1$, a urea transporter gene on chromosome 18q12.3. Hum. Mol. Genet. 20(21), 4282-4289 (2011).

- Key original discovery or early review paper.

74 Goodman SR, Kurdia A, Ammann L, Kakhniashvili D, Daescu O. The human red blood cell proteome and interactome. Exp. Biol. Med. (Maywood) 232(11), 1391-1408 (2007).

- Key original discovery or early review paper.

75 Pasini EM, Lutz HU, Mann M, Thomas AW. Red blood cell (RBC) membrane proteomics - part I: proteomics and RBC physiology. J. Proteomics 73(3), 403-420 (2010).

"I- Key comprehensive review. 
76 Hernandez-Hernandez A, Rodriguez MC, Lopez-Revuelta A et al. Alterations in erythrocyte membrane protein composition in advanced non-small cell lung cancer. Blood Cells Mol. Dis. 36(3), 355-363 (2006).

77 Koren W, Koldanov R, Pronin VS et al. Enhanced erythrocyte $\mathrm{Na}^{+} / \mathrm{H}^{+}$exchange predicts diabetic nephropathy in patients with IDDM. Diabetologia 41(2), 201-205 (1998).

- Key original discovery or early review paper.

78 Weder AB, Delgado MC, Zhu X, Gleiberman L, Kan D, Chakravarti A. Erythrocyte sodium-lithium countertransport and blood pressure: a genome-wide linkage study. Hypertension 41(3 Pt 2), 842-846 (2003).

- Key original discovery or early review paper.

79 Sprague RS, Stephenson AH, Bowles EA, Stumpf MS, Lonigro AJ. Reduced expression of $\mathrm{G}(\mathrm{i})$ in erythrocytes of humans with Type 2 diabetes is associated with impairment of both cAMP generation and ATP release. Diabetes 55(12), 3588-3593 (2006).

80 Antonelou MH, Kriebardis AG, Stamoulis KE, Trougakos IP, Papassideri IS. Apolipoprotein J/clusterin is a novel structural component of human erythrocytes and a biomarker of cellular stress and senescence. PLoS ONE 6(10), e26032 (2011).

81 Saison C, Helias V, Ballif BA et al. Null alleles of $A B C G 2$ encoding the breast cancer resistance protein define the new blood group system Junior. Nat. Genet. 44(2), 174-177 (2012).

- Key original discovery or early review paper.

82 Kasza I, Varady G, Andrikovics $\mathrm{H}$ et al. Expression levels of the ABCG2 multidrug transporter in human erythrocytes correspond to pharmacologically relevant genetic variations. PLoS ONE 7(11), e48423 (2012).

- Key original discovery or early review paper.

83 Kobayashi D, Ieiri I, Hirota T et al. Functional assessment of $A B C G 2$ (BCRP) gene polymorphisms to protein expression in human placenta. Drug Metab. Dispos. 33(1), 94-101 (2005).

84 Depirro R, Fusco A, Lauro R, Testa I, Ferreti F, Demartinis C. Erythrocyte insulin receptors in non-insulin-dependent diabetes mellitus. Diabetes 29(2), 96-99 (1980).

- Key original discovery or early review paper.

85 Santos RF, Palmieri MG, Wajchenberg BL, Azhar S. Insulin-receptor tyrosine kinase activity is decreased in erythrocytes from non-obese patients with NIDDM. Horm. Metab. Res. 26(6), 283-287 (1994).

86 Chapman K, Pullen N, Coney L et al. Preclinical development of monoclonal antibodies: considerations for the use of nonhuman primates. MAbs 1(5), 505-516 (2009).

87 Zola H. Medical applications of leukocyte surface molecules - the CD molecules. Mol. Med. 12(11-12), 312-316 (2006).

"II Key comprehensive review.

88 Le Dantec C, Alonso R, Fali T et al. Rationale for treating primary Sjogren's syndrome patients with an anti-CD6 monoclonal antibody (itolizumab). Immunol. Res. 56(23), 341-347 (2013).

89 Sethuraman C, Simmerson M, Vora AJ, Cohen MC. Flowcytometric immunophenotyping in the diagnosis of pediatric lymphoma: how reliable is it and how can we optimize its use? J. Pediatr. Hematol. Oncol. 32(4), 298-303 (2010).
- Key original discovery or early review paper.

90 Wozniak J. Two methods for the quantitative analysis of surface antigen expression in acute myeloid leukemia (AML). Folia Histochem. Cytobiol. 42(3), 195-199 (2004).

91 Rusak M, Osada J, Pawlus J, ChociejStypulkowska J, Dabrowska M, Kloczko J. Utility of laboratory tests in B-CLL patients in different clinical stages. Int. J. Hematol. 93(6), 736-744 (2011).

92 Sweet SC. Induction therapy in lung transplantation. Trans. Int. 26(7), 696-703 (2013).

93 Waldmann TA. Immunotherapy: past, present and future. Nat. Med. 9(3), 269-277 (2003).

"- Key comprehensive review.

\section{Websites}

101 OECD. Policy issues for the development and use of biomarkers in health. www.oecd.org/sti/biotech/49023036.pdf

102 BIOPARADIGMS ${ }^{\circledR}$. www.bioparadigms.org

103 Human Cell Differentiation Molecules. www.hcdm.org

104 HUGO Gene Nomenclature Committee. CD moleules. www.genenames.org/genefamily/cd.php

105 Genetics home reference. GPCR gene family. http://ghr.nlm.nih.gov/geneFamily/gpcr

106 Genetics home reference. ATP gene family. http://ghr.nlm.nih.gov/geneFamily/atp

107 BIOPARADIGMS ${ }^{\circledR}$. SLC tables. http://slc.bioparadigms.org 